\section{Reflexiones sobre la infección por Zika en Paraguay}

\section{Reflections on Zika infection in Paraguay.}

\section{Sr. Editor:}

En la actualidad el Paraguay, al igual que los demás países de las Américas, se encuentra susceptible a un brote epidémico por virus Zika (ZIKV), otro arbovirus circulante en esta región desde el año 2014 (Tabla 1) y transmitido por Aedes aegypti, ${ }^{1,2}$.

Este virus, a pesar de no ser el causante de tantas muertes como el dengue (DENV) y chikungunya (CHIKV), se ha asociado a microcefalia en recién nacidos, lo que representa un problema de suma importancia para la salud pública ${ }^{3}$. Además, tiene la particularidad de que puede

Tabla 1. Cronología de notificaciones de casos de Zika en América a la OMS (Actualización marzo de 2016)

\begin{tabular}{|c|c|c|}
\hline País & Fecha de notificación a la OMS & Casos confirmados \\
\hline \multicolumn{3}{|c|}{ Febrero de 2014} \\
\hline Chile & & Sin datos \\
\hline \multicolumn{3}{|c|}{ Octubre de 2015} \\
\hline Brasil & & 534 \\
\hline Colombia & & 1612 \\
\hline \multicolumn{3}{|c|}{ Noviembre de 2015} \\
\hline Guatemala & 11 & 105 \\
\hline El Salvador & 24 & 3 \\
\hline México & 26 & 121 \\
\hline Venezuela & 27 & 4 \\
\hline \multicolumn{3}{|c|}{ Diciembre de 2015} \\
\hline Paraguay & 27 & 6 \\
\hline Panamá & 2 & 106 \\
\hline Honduras & 16 & 2 \\
\hline Puerto Rico & 31 & 102 \\
\hline \multicolumn{3}{|c|}{ Enero de 2016} \\
\hline Guyana Francesa & 14 & 102 \\
\hline Barbados & 14 & 9 \\
\hline Ecuador & 14 & 40 \\
\hline Bolivia & 16 & 1 \\
\hline Haití & 18 & 5 \\
\hline República Dominicana & 23 & 18 \\
\hline E.U.A. & 25 & 6 \\
\hline Nicaragua & 27 & 92 \\
\hline Costa Rica & 27 & 3 \\
\hline
\end{tabular}

Fuente: OMS: Cumulative Zika suspected and confirmed cases reported by countries and territories in the Americas, 2015-2016. ser transmitido no sólo por el vector mencionado, sino que se ha evidenciado la transmisión sexual y por otra especie de mosquito ${ }^{4}$.

También se ha observado la predisposición a desarrollar síndrome de Guillain Barré y otros trastornos neurológicos periféricos; sin embargo, esta asociación aún se encuentra en estudio ${ }^{5}$. Actualmente no existe tratamiento antiviral o vacuna específica para la infección por ZIKV, recomendándose sólo tratamiento sintomático tras excluir otras enfermedades ${ }^{6}$.

En vista de la probable asociación de la infección por ZIKV con trastornos neurológicos y malformaciones congénitas, a principios de febrero del presente año la Organización Mundial de la Salud (OMS) convocó a un Comité de Urgencia para evaluar los efectos de la amenaza de esta infección. Los expertos consideraron la necesidad urgente de coordinar los esfuerzos internacionales para investigar y entender mejor esta relación, así como sus patrones de creciente propagación y la amplia distribución geográfica de las especies de mosquitos que pueden transmitir el virus?

De acuerdo a los datos del Ministerio de Salud Pública y Bienestar Social (MSP y BS) de Paraguay, en noviembre de 2015 (semana epidemiológica 46) se informó el hallazgo de ZIKV por RPC-TR en seis muestras provenientes del Departamento de Amambay, distrito de Pedro Juan Caballero, localidad ubicada en la frontera con Brasil ${ }^{8}$.

Dado que las manifestaciones clínicas inespecíficas pueden confundirse con otras enfermedades febriles como dengue y chikungunya, pueden pasar desapercibidos muchos casos de infección por ZIKV ${ }^{5}$. Si bien estas dos infecciones ya eran un grave problema de salud pública, esta nueva enfermedad genera un problema mayor debido a la falta de preparación sanitaria y la asociación con microcefalia fetal en mujeres embarazadas. Dado que la legislación de nuestro país no acepta el aborto terapéutico", el MSP y BS recomienda extremar la precaución de evitar embarazos en la región Amambay, así como viajes a esta zona.

Si bien la microcefalia puede ser causada por ZIKV, debe evaluarse y descartarse otras etiologías infecciosas posibles como la sífilis, toxoplasmosis, virus herpes simplex 1 y 2, VIH, entre otros, así como también etiologías no infecciosas condicionantes como la diabetes gestacional ${ }^{10}$, patologías de relativa frecuencia en el país.

En vista a todo lo anterior, y a que Paraguay es un país con endemias altas de arbovirosis, consideramos imperativo fortalecer, por parte de las autoridades de salud, los sistemas de vigilancia para la detección precoz del virus, afinar los métodos de diagnóstico como la pesquisa temprana de microcefalia por ecografía fetal e implementar proyectos de investigación para contribuir al conocimiento de esta infección. 


\section{Referencias bibliográficas}

1.- Rodríguez-Morales A J. No era suficiente con dengue y chikungunya: llegó también Zika. Archivos de Medicina [Internet]. 2015; 11 (2): 1-4. Disponible en: http://www. archivosdemedicina.com/medicina-de-familia/no-erasuficiente-con-denguey-chikungunya-lleg-tambinzika.pdf . (Fecha de acceso: 3 de marzo 2016).

2.- Nuñez F, Arce S. Zika: ¿La siguiente amenaza? Artrópodos y Salud [Internet]. 2015; 2(1): 20 - 24. Disponible en: http://www.artropodosysalud.com/ Publicaciones/No3-Ene2015/6ZIKA\%20FINAL\% 2016-05-15.pdf. (Fecha de acceso: 3 de marzo 2016).

3.- Rodríguez-Morales A J, Willamil W. El reto de Zika en Colombia y América Latina: Una urgencia sanitaria internacional. Infectio 2016; 20 (2): 59-61.

4.- Rodríguez-Morales A J. Aedes: un eficiente vector de viejos y nuevos arbovirus (dengue, chikungunya y Zika) en las Américas. Rev Cuerpo Méd 2015; 8 (2): 50-2.

5.- Luz K, Viana G, Magalhães R. Febre pelo virus Zika. Epidemiol Serv Saúde 2015; 24 (4): 78-8.

6.- Torres M. Virus Zika, una nueva epidemia en puerta. Rev Biomed [Internet]. 2016; 27: 1 - 2. Disponible en: http://www.medigraphic.com/pdfs/revbio/bio-2016/ bio161a.pdf
7.- WHO. WHO Director-General summarizes the outcome of the Emergency Committee regarding clusters of microcephaly and Guillain-Barré syndrome. 1 february 2016. Disponible en: http://www.who.int/mediacentre/news/ statements/2016/emergency-committee-zika-microcephaly/ en/ (Fecha de acceso: 3 de marzo 2016).

8.- Ministerio de Salud Pública y Bienestar Social. Boletín Epidemiológico $\mathrm{N}^{\circ} 46$. S.E 46. Disponible en: http:// vigisalud.gov.py/wp-content/uploads/2015/12/Boletinepidemi\%C3\%B3logico-SE-46.pdf

9.- Ministerio de Salud Pública y Bienestar Social. Paraguay no apoya la interrupción del embarazo por Zika.

Disponible en: http://www.mspbs.gov.py/v3/paraguay-noapoya-interrupcion-del-embarazo-por-Zika/ (Fecha de acceso: 3 marzo 2016).

10.- Staples J E, Dziuban E J, Fischer M, Cragan J D, Rasmussen $\mathrm{S} \mathrm{A}$, Cannon $\mathrm{M} \mathrm{J}$, et al. Interim guidelines for the evaluation and testing of infants with possible congenital Zika virus infection-United States, 2016. MMWR Morb Mortal Wkly Rep 2016; 65: 63-7.

Carlos Rios-González y Jorge Escobar-Salinas Facultad de Ciencias Médicas, Universidad Nacional de Caaguazú, Coronel Oviedo, Paraguay.

Correspondencia a: Carlos Rios-González carlosmigue_rios@live.com 